\title{
Marine Autonomous Surface Ship - A Great Challenge to Maritime Education and Training
}

\author{
Wang Deling, Wu Dongkui", Huang Changhai, Wu Changyue \\ Merchant Marine College, Shanghai Maritime University, Shanghai, China \\ Email address: \\ dlwang@shmtu.edu.cn (Wang Deling), wudk@shmtu.edu.cn (Wu Dongkui), chhuang@shmtu.edu.cn (Huang Changhai), \\ cywu@shmtu.edu.cn (Wu Changyue) \\ ${ }^{*}$ Corresponding author
}

\section{To cite this article:}

Wang Deling, Wu Dongkui, Huang Changhai, Wu Changyue. Marine Autonomous Surface Ship - a Great Challenge to Maritime Education and Training. American Journal of Water Science and Engineering. Vol. 6, No. 1, 2020, pp. 10-16. doi: 10.11648/j.ajwse.20200601.12

Received: December 15, 2019; Accepted: January 4, 2020; Published: January 21, 2020

\begin{abstract}
As the rapid development of modern science and technology, significant progresses have been made in the research and testing of the Marine Autonomous Surface Ship (MASS). The navigation of traditional ships is based on seafarers, who makes all the decisions and operations. In the future, ships may be controlled and operated autonomously without intervention of human if MASS can reach the level of unmanned control. It can be predicted that the wider application of MASS will bring great changes to the shipping industry, and pose great challenges to seafarers knowledge structure, talent cultivation and etc. The application of new technologies on MASS, i.e. integrated bridge systems, environmental information perception, collision avoidance path planning, cyber-physical systems, track control, internet of things, cloud computing, big data, automation, remote control, satellite and communication, fault diagnosis and etc., will in no doubt bring new requirements to seafarers' navigation knowledge and skills, and pose great challenges on the Maritime Education and Training (MET). Based on the new science and technologies to be applied on ships, this paper analyses the competence requirements of seafarers on MASS in different development level, predicts the impacts of MASS on MET and put forward the direction of seafarers' MET in future.
\end{abstract}

Keywords: MASS, Seafarers, Maritime Education and Training, Challenges, Automatic Control

\section{Introduction}

Human beings have enjoyed a nearly 5000 years history of using ships as means of transport from ancient canoes to modern ships. Each leap in shipping technology has imposed a certain impact on shipping industry. Marine Autonomous Surface Ship (MASS) is the result of modern science and technology. The development of MASS involves the integrated application of technologies such as cyber-physical systems, Integrated Bridge Systems, environmental information perception, collision avoidance path planning, track control, internet of things, cloud computing, big data, automation, network information security, remote control, satellite and communication, fault diagnosis technologies for equipment and systems and hull condition monitoring and etc..

In view of the rapid development of ship technologies, in order to cope with the new requirements imposed by MASS on international maritime conventions, rules and standards in the future, International Maritime Organization (IMO) has gradually begun to develop specifications related to autonomous vessels. The norm-setting work is mainly divided into two steps. The first step is to review existing IMO rules and regulations, list the documents and provisions to be revised by IMO, and analyze and define how current rules are or aren't accessible to different levels of MASS, and identify if those documents and provisions would have the possibility of impeding the research and development process of MASS. This step has been completed by IMO. In the second step, considering the human factors, technical and operational factors, analysis will be made to determine the best way to solve the legislation problems of MASS. [1]

It is reported that the first fully autonomous ship will be put into operation around year 2020. The development of MASS will greatly change the traditional navigation mode and will have a great impact on the international maritime legal system. 
In order to make the international maritime conventions, codes and standards meet the needs of the development of MASS, IMO began to study on MASS from the legislative point of view in the 99th session of the Maritime Safety Committee (MSC). [2, 3]

At the 100th session of MSC meeting in December 2018, it was considered that seafarers should be prepared for the development of MASS. The new technologies of MASS may be achieved in less than five years. Nevertheless, the challenges that need to be faced are: non-balance between the laws, regions and nations, search and rescue, and the level and reliability of new technologies. Appropriate maritime education and training (MET) is essential to provide security for seafarers' future career.

The operation of traditional ships is based on human, who makes all the decisions and operations. In the future, ships may be controlled and operated autonomously without intervention of human if MASS can reach the level of unmanned control. [4] It can be predicted that the wider application of MASS will bring great change to the shipping industry, and pose great challenges to seafarers knowledge structure, talent cultivation and etc.

Close attention has been paid to the challenges that the development of MASS may bring to the Maritime Education and Training (MET). In order to study the implications of MASS on the Seafarer's career, Nautilus Federation and ITF conduct a survey by questionnaires and conclude "it's not surprising that the majority of seafarers (84\%) consider MASS as a threat to seafarer's jobs. However, the research report does not tell how the development of MASS affect the seafarer's occupation, nor their impact on MET. By studying the course of ship technological development, this paper attempts to explore the challenges and changes that the development of MASS may bring to MET, from a macro perspective, attempts to predict the impacts of MASS on ship navigation modes, the required knowledge structure of seafarers, maritime education and training, curriculum design through analysis and comparison of maritime conventions and regulations, and the application of new technologies on MASS.

\section{Prediction and Analysis of the Development of MASS}

\subsection{Definition and Autonomy Level of MASS}

Nowadays, Marine Autonomous Surface Ship is under the stage of testing and improving. In the proposal of related principles about Marine Autonomous Surface Ship in MSC 99th Conference submitted by Japan, the term "unmanned ship" refers to a ship that has no crew members on board. Depending on the level of automation, the ship may be operated either remotely by one or more shore-based remote controllers, or in a fully automated mode without human intervention. The level of automation of the operation is not fixed but may change during a single voyage.

In December 2018, in the 100th session of Maritime Safety Committee meeting (MSC100), MASS was officially defined from the view of legislation as a ship that can operate independently of human-machine interaction in some extent. According to the automation level, MASS was divided into four levels. See table 1 below "Automation level (AL) of MASS". [5]

Table 1. "Automation level (AL) of MASS".

\begin{tabular}{|c|c|c|}
\hline $\begin{array}{l}\text { Automation } \\
\text { level (AL) }\end{array}$ & Description & Features \\
\hline AL-1 & $\begin{array}{l}\text { Ships with process } \\
\text { automation and } \\
\text { decision support }\end{array}$ & $\begin{array}{l}\text { Equipped with some systems or equipment that can help seafarers to realize the process automation and decision } \\
\text { support of navigation tasks. The navigation decisions of ships are made by the seafarers themselves, and the } \\
\text { information obtained from the outside world only plays a supplementary role in the decision-making of seafarers. }\end{array}$ \\
\hline AL-2 & $\begin{array}{l}\text { Remote-controlled } \\
\text { ships with seafarers } \\
\text { on board }\end{array}$ & $\begin{array}{l}\text { Equipped with remote control systems or equipment that can help off-board personnel (e.g. personnel on shore or } \\
\text { other equipment) complete the task of navigation. The navigation decisions of ships are made by the off-board } \\
\text { personnel, and seafarers are supposed to operate in accordance with the commands by remote-controlled personnel. }\end{array}$ \\
\hline AL-3 & $\begin{array}{l}\text { Remote-controlled } \\
\text { ship without } \\
\text { seafarers on board }\end{array}$ & $\begin{array}{l}\text { Equipped with remote control systems or equipment that can help off-board personnel (e.g. personnel on shore or } \\
\text { other equipment) complete the task of navigation. The navigation decisions of ships are made by the off-board } \\
\text { personnel completely, and there are no seafarers on board }\end{array}$ \\
\hline AL-4 & $\begin{array}{l}\text { Remote-controlled } \\
\text { ship without } \\
\text { seafarers }\end{array}$ & $\begin{array}{l}\text { The operating system of MASS in this level calculates consequences and risks. The system is able to make } \\
\text { decisions and determine actions by itself. The operator on shore is only involved in decisions, if the system fails or } \\
\text { prompts for human intervention, in which case the autonomy level will shift to level R or RU, depending on } \\
\text { whether there is crew on board or not. }\end{array}$ \\
\hline
\end{tabular}

Note: In table 1, AL-Automation level; R - Remote control with seafarers on board; RU-Remote control without seafarer on board.

\subsection{Features of MASS}

MASS is a trend of the shipping development, and with the improvement of the ship automation, the shipping mode will have great changes. [6] MASS are predicted to have the following features:

(1) With perceptive ability, the ability to perceive the information of the ship itself and the surrounding environment;
(2) With memory and thinking ability, that is, the ability to store perception information and management knowledge, and the ability to analyze, calculate, compare, judge, associate and make decisions with existing knowledge;

(3) With learning and adaptive ability, that is, through the interaction of expert knowledge and environment, constantly learn and accumulate knowledge and adapt to 
the change of environment;

(4) With the ability to make decisions, that is, to respond to one's own situation and external environment, to make decisions and guide the on-shore personnel, and even to control the ship. [7]

\subsection{Analysis of Key Technologies to Be Used on MASS}

Based on the features of MASS as discussed in paragraph 2.2, MASS involves the integrated application of technologies such as cyber-physical systems, Integrated Bridge Systems, environmental information perception, collision avoidance path planning, track control, internet of things, cloud computing, big data, automation, network information security, remote control, satellite and communication, fault diagnosis technologies for equipment and systems and hull condition monitoring and etc. [8]

Analysis of Key technologies for MASS is as below

1) Cyber-physical Systems

Cyber-physical systems (CPS) are the integration and interaction between computing processes and physical processes. In other words, it can detect and control the physical process through embedded computer and network, and realize the influence of physical process on calculation process through feedback loop. Different from the traditional concepts of computing system and physical system, it combines the information world with the physical world through self-adaptive and feedback closed-loop control, and mainly considers the performance optimization in function. It is an intelligent technology integrating computing, communication and control technology (3C), which has the characteristics of real time, security, reliability and high performance. Autonomous ship is a complex, heterogeneous, and highly reliable application system that meets the requirements of CPS. The realization of intelligent needs the support of multi-source isomerism information, such as the vessel's own navigation status, surrounding environment, equipment status, and inter-vessels, vessel-to-shore interaction.

\section{2) Integrated Bridge System}

The Integrated Bridge System is an integrated system, which is reflected in various functions such as perfect navigation, driving control, collision avoidance, information centralized display, alarm monitoring, communication, shore station support, navigation management and control automation. It is convenient for the driver and shore-based personnel to observe and manipulate, and optimize the information of each equipment at the same time, so that the Integrated Bridge System can play a greater role in ensuring the safe navigation of the vessel and reducing the personnel cost than when the equipment is used alone. The current IBS has entered the stage of artificial intelligence and mobile internet development, and the new generation of IBS will undergo a major change under the guidance of information technology, network technology, communication technology and computer technology.

3) Environmental information perception

At present, information of the fairway, surrounding traffic, other vessels and own vessel navigation status can be obtained by means of the existing navigation equipment such as radar, AIS, electronic chart and GPS, and etc.. The water depth, water flow velocity, wind speed and wind direction are obtained by means of hydrological sensors such as depth sounder, ocean current meter and anemometer and etc.. For non-vessel obstacles, laser scanners and radar can also be used for fusion recognition. In the process of environmental perception, the information of different sensors or devices may be redundant, conflicting and missing. It is necessary to realize the reliable identification of the environment by means of information fusion theory.

4) Collision avoidance path planning

When the vessel is sailing, it is necessary to follow the vessel collision avoidance rules. Considering the safety of the collision avoidance path, it is also necessary to consider making the route shorter, more energy efficient and more time-saving. In the early stage, the collision avoidance path planning method based on expert system was widely used. After the 1990s, with the rapid development of intelligent algorithms, fuzzy control, neural networks and artificial potential fields have been used in the field of vessel collision avoidance path planning. However, different intelligent algorithms have their own advantages and disadvantages. The application of multiple intelligent algorithms to avoid collisions has become the development trend of current vessel collision avoidance path planning. [9]

5) Track control

The traditional vessel track control adopts the track automatic rudder method and has experienced four stages: mechanical automatic rudder, PID automatic rudder, adaptive automatic rudder and intelligent automatic rudder. In response to these demands, some advanced control algorithms have begun to be applied to vessel track control, such as Line of Sight (LOS) navigation based on state feedback, Model Predictive Control (MPC) based on optimal control theory method, etc.

6) Internet of Things

Based on the communication network such as the internet and mobile communication networks, the Internet of Things uses the intelligent objects with sensing, communication and computing capabilities to automatically acquire various information of the physical world. It interconnects all physical objects that can be independently addressed, realizes comprehensive sensing, reliable transmission, and intelligent analysis and processing, and constructs an intelligent information service system in which people and things, things and things are interconnected. [10] In the field of navigation, the application of Global Positioning System (GPS), ARPA (Automatic Radar Plotting Aid) radar, AIS, electronic chart display and information system, integrated bridge system, radio frequency identification (RFID), video surveillance and other technical means has made the vessel develop rapidly in the direction of informatization and intelligence. [11] The emergence of the Internet of Things has provided new ideas for the development of autonomous vessels.

7) Cloud computing 
Cloud computing is the development of distributed computing, parallel computing, and grid computing. Real-time and dynamic analysis of the massive amount of information collected by a large number of sensing devices at different times during vessel navigation, and the aggregation, splitting, statistics, and backup of such information require cloud computing with elastic growth storage resources and massive parallel computing capabilities as a support.

8) Big data

The application of big data is the process of using the results of big data analysis to provide users with decision-making and mining potential value. Regional or dedicated data monitoring centers have emerged in the shipping industry. For example, international shipping companies such as China Ocean shipping Group have realized the operation status of their vessels on a global scale. Europe's information collaboration service concept for supporting inland navigation, traffic management, transportation management and multi-modal transport - Harmonized River Information Services (RIS) provides users with static information such as electronic maps, laws and regulations, and dynamic information such as vessel registration and vessel position, cargo information, and estimated arrival time.

The application of the those technologies above on ships is the guarantees to realize the development of different levels of MASS.

\subsection{Development of Typical MASS}

The development of MASS has been experiencing different stages, from the engine room automation to the self-navigation and automatic obstacle avoidance, which represents emergence of the embryonic form of ship intelligence, then to full automation in the future taking into account the energy efficiency management. MASS is developing into a stage of comprehensive intelligent vessels. [8] At present, the preliminary unmanned ships has appeared. In this paper, according to the chronological order, the representative ships since the beginning of the embryonic form of development in $1960 \mathrm{~s}$ are counted, and the following table is formed. The table can clearly show the course of independent ship development and the trend of future development.

Table 2. Representative Vessels in the Development of Autonomous Vessels.

\begin{tabular}{|c|c|c|c|}
\hline Year & $\begin{array}{l}\text { Country } \\
\text { / Region }\end{array}$ & Vessels & Features \\
\hline 1964 & Japan & "SELEM DAM 65", tanker & Engine room centralized control, engine remote controlled on the navigation bridge. \\
\hline 1970 & Japan & "Starlight Maru", tanker & $\begin{array}{l}\text { The control and management of the entire vessel is achieved through various subroutines and } \\
\text { interfaces. }\end{array}$ \\
\hline 1985 & China & $\begin{array}{l}\text { "Berlin Express", container } \\
\text { vessel }\end{array}$ & $\begin{array}{l}\text { Automatic steering system, automatic navigation system, vessel management center, } \\
\text { comprehensive management of the whole vessel was achieved through the computer system. }\end{array}$ \\
\hline 2008 & China & $\begin{array}{l}\text { "Tianxiang No. 1", offshore } \\
\text { exploration vessel }\end{array}$ & Intelligent navigation, radar search, satellite applications, image processing and transmission \\
\hline 2012 & EU & MUNIN & Unmanned vessel \\
\hline 2012 & China & $\begin{array}{l}\text { Automatic unmanned } \\
\text { sampling vessel }\end{array}$ & $\begin{array}{l}\text { Robot control technology, automatic navigation technology, ultrasonic intelligent wall protection } \\
\text { barrier technology, } 3 \mathrm{G} \text { network / GPRS real-time communication technology. With autonomous } \\
\text { navigation, automatic obstacle avoidance, network management and other advantages }\end{array}$ \\
\hline 2014 & UK & $\begin{array}{l}\text { "Mayflower", marine } \\
\text { autonomous vessel }\end{array}$ & Unmanned trimaran sailing boat \\
\hline 2016 & USA & "Sea Hunter" & Unmanned vessel \\
\hline 2016 & Norway & "Hronn" light marine vessel & Unmanned vessel \\
\hline 2017 & China & "Da Zhi" & Intelligent navigation, intelligent engine room, intelligent energy efficiency management, etc. \\
\hline 2018 & Norway & Yara Birkeland & Unmanned, electric, container \\
\hline 2020 & Europe & One Sea & Independent control of marine ecosystem by enterprises, completely remotely controlled \\
\hline 2020 & UK & Rolls-Royce & Remotely controlled unmanned vessel \\
\hline 2025 & Europe & One Sea & Autonomous commercial operation \\
\hline 2035 & UK & Rolls-Royce & Unmanned ocean-going merchant vessel \\
\hline
\end{tabular}

In addition, in 2016, Norway established the world's first MASS test area. In 2018, China officially launched the offshore test site for the unmanned vessels in Wanshan, Zhuhai in Guangdong province. Qingdao also began to build a marine autonomous vessel test area. The construction of autonomous vessel offshore test sites will in no doubt accelerate the process of vessels' intelligence and promote the technological development of MASS.

\section{Analyses of Challenges of MASS on MET}

\subsection{Analyses of Knowledge and Skills Needed to Manage and Operate MASS}

The current STCW convention and code stipulates the requirements of the training, certification, watch-keeping and 
competence for seafarer. MET in most countries in the world are basically conducted in accordance with the requirements of STCW convention and code. As to the positions on board ships, seafarers are divided in STCW code into three levels: management level, operation level and support level, and the table of KUP (Knowledge, Understanding, Proficiency) in STCW code specifies the competence requirements of the three levels. [12]

The application of new knowledge and new technology on MASS is bound to produce new requirements for the competence of seafarers. The requirements of the current STCW convention and code will not meet the development of MASS in no doubt. [13] In order to further analyze the specific influence of MASS on seafarers' MET, this paper, according to the development trend of MASS, divides the knowledge and skills needed by navigators ${ }^{1}$ in the future to manage and operate MASS into three aspects: Ability, Knowledge and Technology. Each aspect includes a number of elements (see table 3 below). However, In the existing traditional MET curriculum, the new knowledge and technology related to MASS are not included, which will not meet the needs of MASS development, making it urgent to reform in MET. See Table 3 below "Knowledge and skills needed to manage and operate MASS in the future".

Table 3. Knowledge and skills needed to manage and operate MASS in the future.

\begin{tabular}{|c|c|c|}
\hline $\begin{array}{l}\text { Classification of } \\
\text { Knowledge and } \\
\text { skills in relation } \\
\text { to MASS } \\
\end{array}$ & Knowledge and skills & $\begin{array}{l}\text { Whether included in the } \\
\text { existing MET curriculum? }\end{array}$ \\
\hline \multirow[b]{3}{*}{ Aspect of ability } & $\begin{array}{l}\text { Leadership and } \\
\text { communication }\end{array}$ & Yes, \\
\hline & Obedience and execution & Yes \\
\hline & $\begin{array}{l}\text { Psychological stress } \\
\text { resistance }\end{array}$ & $\begin{array}{l}\text { Not exactly, as the number of } \\
\text { ship manning decreases, } \\
\text { problems of "psychological } \\
\text { stress" will become more } \\
\text { prominent. }\end{array}$ \\
\hline \multirow{5}{*}{$\begin{array}{l}\text { Aspect of } \\
\text { knowledge }\end{array}$} & $\begin{array}{l}\text { Traditional nautical } \\
\text { knowledge }\end{array}$ & Yes \\
\hline & $\begin{array}{l}\text { Network communication } \\
\text { knowledge }\end{array}$ & $\begin{array}{l}\text { Not exactly, this knowledge } \\
\text { is only reflected in GMDSS } \\
\text { courses. }\end{array}$ \\
\hline & $\begin{array}{l}\text { Automatic control } \\
\text { knowledge }\end{array}$ & $\begin{array}{l}\text { Not exactly, there are only } \\
\text { some automation knowledge } \\
\text { in ships' bridge and engine } \\
\text { room control in existing } \\
\text { MET. }\end{array}$ \\
\hline & Data mining knowledge & No \\
\hline & $\begin{array}{l}\text { Artificial intelligence } \\
\text { knowledge }\end{array}$ & No \\
\hline \multirow{5}{*}{$\begin{array}{l}\text { Aspect of } \\
\text { technology }\end{array}$} & Autonomous navigation & No \\
\hline & Fault diagnosis & No \\
\hline & Remote control & No \\
\hline & $\begin{array}{l}\text { Environmental } \\
\text { information perception }\end{array}$ & No \\
\hline & Internet of Things & No \\
\hline
\end{tabular}

1 The word "navigator" is used here instead of "seafarer", because "seafarer" refers to persons manned on board ships to management and navigate the ship. However, when MASS develops to a certain stage in the future, the ship will no longer be manned, and it would be inappropriate to use the word of "seafarer" while there is no seafarer on board.
Those knowledge and skills listed in table 1 are essential and minimum requirements for navigators in future to manage and operate MASS. The mastery degree of the knowledge or skills required by navigators varies according to position of navigator and the level of MASS.

\subsection{Impacts of MASS on MET}

\subsubsection{Impacts of MASS on the Ship's Manning}

The division of four levels of autonomy, in essence, is that the ship's navigation behavior depends on the division of the level of the ship's crew on board, from no longer entirely depending on the shipboard crew to completely getting rid of crew on board ships. In the first level of MASS, the ships' manning is decreased. In the level of remote-controlled ships, the future "seafarers" will be divided into two types: "shore based operator" and "seafarers on board ships". In the full autonomous level, the ships will sail autonomously, under which condition there will be no seafarers on board ships. Thus it can be seen that the reduction of ship manning is a general trend, and the enrollment scale of navigation major will be reduced with the development of MASS. [14] The International Shipping Association (ICS) forecasts that, ideally, there will be about 1000 automatically navigated ships and 2000 semi-automatically navigated ships in 2025 , which could reduce the demand for seafarers by 30,000 to 50,000 . [15]

In terms of horizontal structure, the development of MASS will bring about the adjustment of seafarer type structure. In accordance with the the STCW convention and code, seafarers are basically divided into three types: deck crew members in charge of ship navigation and cargo transportation (Major of nautical technology); engine room crew members responsible for ship propulsion and machinery system (Major of marine engineering); and electrical, electronic and control personnel (Major of electrical, electronic and control engineering) responsible for the electrical, electronic installation and control system of the ships. While in higher levels of MASS, the seafarers will not be classified according to the workplaces, and ship control personnel will be divided into two types: "shore-based" personnel and "shipboard crew". The shore-based personnel will be responsible for the navigation of ships by remote control, and the shipboard crew will undertake multiple tasks such as navigation and machine maintenance.

In terms of longitudinal structure, the development of MASS will bring about the adjustment of the hierarchical structure of maritime talents. At present, the cultivation of the maritime talents has three levels: technical secondary, high-vocational education and undergraduate. Whether from view of human capital or from the view of technological development, this occupation requires higher technical conditions, and the society needs more high-quality talents. The development of MASS needs more skilled maritime talents, so the proportion of maritime talents at the levels of technical secondary will continue to shrink, and those of high-vocational and undergraduate level will occupy the mainstream. According to $<$ the Annual Development report of 
Chinese seafarers $>$ released by the Ministry of Transport of China, the proportion of maritime talents from technical secondary school has dropped from 17.77 percent in 2001 to 8.08 percent in 2017 , and this proportion will continue to decline in the future.

\subsubsection{Impacts of MASS in Different Level on the Requirement of MET}

Through the study on the technologies required by MASS and the content in table 3 , different levels of MASS have different impacts on the future maritime education and training.

1) Impacts of ships with process automation and decision support on MET

Ships with process automation and decision support are equipped with some systems or equipment that can help seafarers to achieve the process automation and decision support of navigation tasks. The navigation decision-making of ships is entirely made by the seafarers themselves, and the information obtained from outside only plays a supplementary role in the decision-making of seafarers.

The operation of ship with process automation and decision-support remain largely dependent on the operation and management of seafarers. MASS in this level has limited impacts on modern maritime education and training. However, as the automatic control system and decision support system are widely applied in this type of ship, new requirements will be put forward for the knowledge system and training method of education training.

2) Impacts of Remote-control ships with crew on MET

When the marine autonomous surface ships develop to the second level, i.e. the Remote-control ships with crew, the personnel allocation of the ships will be greatly changed compared with that of traditional ships: shore-based Remote-control personnel appeared and the number of the personnel on board was reduced, and the working mode and division of labor will greatly be changed. Marine navigators need to complete the learning or practice of relevant knowledge and skill in accordance with the requirements in table 3, and meet the corresponding standards of competency.

As can be seen from table 3, the knowledge structure required by maritime navigators on Remote-control ships with crew members has changed greatly. In addition to the corresponding traditional maritime knowledge, marine navigators should master new knowledge and technology related to marine autonomous surface ship or apply them in practice to different degrees, such as network information knowledge, automation knowledge, information physical system knowledge, big data knowledge, autonomous navigation and collision avoidance technology, remote control knowledge etc, which will have a considerable impact on the future maritime education and training, requiring the future maritime education and training to include the above new knowledge and technology in addition to the traditional maritime knowledge.

3) Impacts of Remote-control ships without crew on MET

Ships with this stage are equipped with remote control system or facilities that can help personnel being not on board such as remote control navigators on shore or on other facilities to fulfill navigation tasks. Decisions will basically be made by personnel being not on board and the ship will be unmanned.

Compared with the Remote-controlled ships with crew, the Remote-control ships without crew are completely dependent on the operation of the qualified personnel on shore. Therefore, the qualified personnel on shore need to have a deeper understanding of the knowledge of network information technology and automation technology, as well as a extensive knowledge reserve to cope with the remote and changeable marine navigation environment.

4) Impacts of full autonomous ships on MET

Ships in this level are equipped with the system or equipment that can enable it to accomplish the tasks of navigation autonomously. The decision-makings for ship operations are completed autonomously. There is no crew on the ship. Control personnel on shore mainly play the role of monitoring the ship's navigation performance, when necessary, can get involved in controlling the ship. [16]

Higher requirements have been put forward for suitable personnel of full autonomous ships. The supervisors need to be proficient in all the knowledge and skills listed in paragraph 2.3 .

\section{Conclusion}

As the rapid development of modern science and technology, significant progresses have been made in the research and testing of the Marine Autonomous Surface Ship (MASS). The navigation of traditional ships is based on seafarers, who makes all the decisions and operations. In the future, ships may be controlled and operated autonomously without intervention of human if MASS can reach the level of unmanned control. It is in no doubt that the wider application of MASS will bring great changes to the shipping industry, and pose great challenges to seafarers knowledge structure, maritime talent cultivation and etc., thus posing great challenges on the Maritime Education and Training. As is analyzed above, basically those challenges on MET are reflected on the following two aspects:

1) Application of new technologies on MASS requires higher-standard maritime talents

Shipping is now stepping into the first level of MASS, i.e. ships with the process automation and decision support. MASS in this stage is mainly dependent on operation and management of crew, which has a limited impact on modern maritime education and training. As the automatic control system and decision support system have been applied widely, new knowledge and skill needs to be increased in the existing education training.

However, in terms of the current growth momentum of technologies, ships will rapidly develop into a higher level in the coming decades, and by then traditional knowledge and skills of ship navigation will not meet the requirements for MASS operation. In addition to the traditional maritime knowledge, 
ships' navigators are to be required to master new knowledge and technology related to MASS such as network information knowledge, automation knowledge, information physical system knowledge, big data knowledge, autonomous navigation and collision avoidance technology, remote control knowledge, etc.

Maritime universities, colleges, training institutions and maritime authorities are suggested to closely track the development of MASS and provide relative new knowledge and improve modes of maritime education in order to produce talents suitable for the development of navigation technology.

2) Mode of MET need to be adjusted to adapt to different levels of MASS

The division of four levels of autonomy, in essence, is that the ship's navigation behavior depends on the ship's manning, in other words, operation of ships evolve gradually from entirely depending on the shipboard crew to completely getting rid of crew. The development of MASS is to bring about the adjustment of seafarer type and the hierarchical structure of maritime talents.

Different from traditional ship manning mode, in higher levels of MASS, ship navigators will be divided into two types: "shore-based" personnel and "shipboard crew". The shore-based personnel will be responsible for the navigation of ships by remote control, and the shipboard crew will undertake multiple tasks such as navigation and machine maintenance. Therefore, design of maritime curriculum system shall be adjusted to include new skills and knowledge required by MASS.

What's more, The development of MASS needs more higher standards maritime talents, so the proportion of maritime talents at the levels of technical secondary will continue to shrink, and those of high-vocational and undergraduate level will occupy the mainstream. Therefore, it is suggested that MET should closely track and follow the development of MASS, forecast the supply and demand for seafarers, dynamically control the scale of maritime talent education, reshape the curriculum system, renew the teaching content, promote innovation of the education mode, and improve the educational quality of maritime talents to adapt to the development of MASS.

\section{References}

[1] IMO. MSC 98/23/Add.1/Corr.1-Report of the maritime safety committee on its ninety-eighth session, Maritime safety committee (MSC), 98th session, 7-16 June 2017 [EB/OL] [2017-06-16]. http://www.imo.org/en/MediaCentre/Meeting Summaries/MSC/Pages/MSC-98th-session.aspx.

[2] IMO. MSC 99/22/Add.-Report of the maritime safety committee on its ninety-ninth session, Maritime safety committee (MSC), 99th session, 16-25 May 2018 [EB/OL]. [2018-05-25].

http://www.imo.org/en/MediaCentre/MeetingSummaries/MSC /Pages/MSC-99th-session.aspx.

[3] IMO. (2018). MSC 99/INF.3 - Final Report Analysis of Regulatory Barriers to the use of Autonomous Ships, submitted by Denmark. P67.

[4] CHWEDCZUK M. Analysis of the legal status of unmanned commercial vessels in U.S. admiralty and maritime law $[\mathrm{J}]$, Journal of Maritime Law and Commerce, 2016 (47).

[5] WU Qing, WANG Le, LIU Jialun. Research status and prospects of autonomous surface cargo ships [J]. CAAI Transactions on Intelligent Systems, 2019, 14 (01): 57-70.(In Chinese)

[6] Technical University of Denmark. (2017). A pre-analysis on autonomous ships. P 14.

[7] Maritime UK (2017). An Industry Code of Practice: Maritime Autonomous Surface Ships up to 24 metres in length (Version 1.0). P 15 .

[8] LI Wenhua, ZHANG Junyan, LIN Shanying. The Development Path of Maritime Autonomous Surface Ships Technology [J]. SHIP ENGINEERING, 2019, 41 (07): 64-73. (In Chinese).

[9] Yanzhuo Xue, D. Clelland, B. S. Lee, Duanfeng Han. Automatic simulation of ship navigation [J]. Ocean Engineering, 2011, 38 (17).

[10] PORATHE T. Maritime unmanned navigation through intelligence in networks: the MUNIN project [R]. 2013: 177-183.

[11] Li Xin, Jia Guixi, Wen Shiyun, Feng Jiankui, Song Jiatai. Research on the control strategy of unmanned tracking ship based on GPS [P]. Control Conference (CCC), 2012 31st Chinese, 2012.

[12] IMO. STCW including 2010 Manila amendments: STCW convention and STCW code [M]. London, International Maritime Organization, 2014.

[13] VEALR, TSIMPLISM. The integration of unmanned ships into the lex maritime [J], Lloyd's Maritime and Commercial Law Quarterly, 2017 (2).

[14] TOMMI ARO, LAURI HEISKARI. Challenges of unmanned vessels [D]. University of Applied Sciences, 2017.

[15] Lu Mei, Sun Yuqing. China's Maritime Education Facing the Age of MASS [J]. Maritime Education Research, 2019, 36 (02): 1-6. (In Chinese).

[16] CMI. Maritime law for unmanned craft [EB/OL]. [2017-08-19]. http://www.comitemaritime.org/Maritime-Law-for-Unmanned -Craft//0,2715,11533,00,html. 